\title{
Predicting the severity of Spodoptera litura on groundnut in relation to climatic variability using ordinal logistic model
}

\author{
GIRISH K. JHA ${ }^{1}$, GAJAB SINGH ${ }^{1}$, S. VENNILA ${ }^{2}$ M. SRINIVASA RAO ${ }^{3}$, H. PANWAR ${ }^{2}$ and M. HEGDE ${ }^{4}$ \\ ${ }^{1} I C A R$-Indian Agricultural Research Institute, New Delhi- 110012 \\ ${ }^{2}$ ICAR-National Research Centre for Integrated Pest Management, New Delhi-110 012 \\ ${ }^{3} I C A R$-Central Research Institute for Dryland Agriculture, Hyderabad- 500059 \\ ${ }^{4}$ University of Agricultural Sciences, Dharwad, Karnataka -580 005 \\ E-mail : girish.stat@gmail.com
}

\begin{abstract}
In this paper, an ordinal logistic regression model was developed for predicting the severity of tobacco caterpillar, Spodoptera litura (Fabricius) on groundnut using the pest dynamics vis a vis climatic data of twenty five years (1990-2014) pertaining to Kharif (26 to 44 standard meteorological weeks $(\mathrm{SMW})$ ) season of Dharwad (Karnataka). Trend analysis of climatic data using Mann-Kendall non parametric test showed that mean and minimum temperatures, and rainfall to be increasing while morning and evening relative humidity and their mean to be decreasing over time. The weekly male moth catches of S. litura (nos./trap/week) during maximum severity period (34 SMW) was modeled with climatic variables lagged by two weeks. The developed model indicated that the maximum temperature and morning relative humidity prior to two weeks contributed significantly to the occurrence of high level of pest attack. Results suggested that for each degree increase in maximum temperature during 32 SMW, the odds of being high pest attack (as opposed to lower or medium) increased by a multiple of 8.6 as compared to the odds of being high or medium (as opposed to low) increasing by 6.4 times for each per cent rise in the morning relative humidity.
\end{abstract}

Keywords: Trend analysis, Mann-Kendall test, Ordinal logistic model, proportional odds model, Spodoptera litura

Groundnut, also known as peanut (Arachis hypogaea L.) is one of the important oilseed crops grown throughout the world considering its economic and nutritional importance. India is the second largest groundnut producing country $(7.04 \mathrm{mt})$ after China $(16.66 \mathrm{mt})$ having forty three per cent share to the total area under groundnut cultivation ( $11.95 \mathrm{~m} \mathrm{ha}$ ) in Asia and twenty per cent $(23.9 \mathrm{~m} \mathrm{ha}$ ) of the World. India has about twenty five and sixteen per cent share to Asia $(23.3 \mathrm{mt})$ and global $(36.4 \mathrm{mt})$ groundnut production, respectively (FAOSTAT, 2014). In India, groundnut is mostly grown as a Kharif crop and contributes to 33 per cent of the total oilseed production $(32.88 \mathrm{mt})$ (GoI, 2014). Karnataka is the fifth largest producer of the crop with Gujarat, Andhra Pradesh, Tamil Nadu and Rajasthan occupying the higher positions. Dharwad district of Karnataka is an area intensively cultivating groundnut. The tobacco caterpillar (Spodoptera litura Fabricius) is a polyphagous insect-pest attacking important commercial crops like groundnut, cotton and sunflower throughout the world and has shown increasing incidence in the recent times with its outbreaks during 2005, 2008 and 2009 in India
(Prasad et al., 2013). Both gregarious and solitary feeding by early and late $S$. litura larval stages reduces the leaf area for photosynthesis which in turn limits the yield potential of the crop through defoliation. Economically, S. litura is an extremely serious pest, as its larvae can defoliate groundnut crop. Fifteen per cent out of Rs 8,63,884 million loss per annum due to insect pests in Indian agriculture is accounted for groundnut crop (Dhaliwal et al., 2010). S. litura in a cropping systems is commonly monitored by deploying pheromone traps (five/ha) to obtain information on the initiation and population levels during the cropping season (NCIPM-ICAR, 2011). Population levels of insects monitored regularly over a long period across many seasons aid in the development of forewarning models. The early forewarning of the insect-pest and disease is not only essential for detection of their severity level but also for the timely utilization of integrated pest management practices by which crop damage can be minimized to a greater extent. Climatic variables as exogenous factors play an important role in determining the insect-pest abundance and distribution and thus the damage to the crop. 
Linear and nonlinear statistical techniques have been used to predict how the changes in weather variables could modify the abundances and distribution of insect pest (Porter et al., 1991, Cammell and Knight, 1992). These effects could either be direct through the influence of weather have on the insects physiology or may be mediated by host plants, competitors and natural enemies. In recent years, studies have also been conducted to analyze the trend of weather variables at national and global scale (Roy and Balling 2004,Yadav et al., 2014).(Rao et. al.2014) indicated that changing climate scenarios in near future (2021-2050) will influence the life cycle of S. litura which in turn will increase the pest incidence in future. However, the impact of weather variables on pest population at the regional level can provide more realistic behavior of weather and pest population dynamics.

Multiple linear regression (MLR) models are appropriate only when the dependent variable is of quantitative nature. However, describing the pest severity into ordinal qualitative categories (such as low, medium and severe) instead of absolute numbers of pests not only circumvents the problem of assumptions of parametric statistical tests but makes it more meaningful for advisory purpose to the groundnut growers. In this approach, the response variable becomes polychotomus and these variables can be classified in to multinomial or ordinal scale. While binary logistic regression is employed for response variable having only two categories (e.g., low and high), ordinal logistic regression(OLR) is preferred for the variables of polychotomous nature based on their order of magnitude over the multinomial logistic regression as OLR provides parsimonious results (Agresti, 2002, Anderson, 1984). Among several existing regression models for ordinal responses (Ananth and Kleinbaum, 1997), the proportional odds model is frequently used by the researchers due to its strong assumption of proportionality in the log-odds ratio for the regression coefficients. Very few studies have been conducted to develop pest prediction model using ordinal data. Present study attempts to develop an OLR model to identify the influence of weather variables towards the development of $S$. litura population in the groundnut cropping system of Dharwad district of Karnataka.

\section{MATERIALS AND METHODS}

\section{Data accrual}

The pest and weather data of groundnut cropping system of Dharwad $\left(15^{\circ} 28^{\prime} \mathrm{N} \& 75 \mathrm{R}^{\circ} 02^{\prime} \mathrm{E}\right)$ of Karnataka corresponding to the Kharif season (26 to 44 standard meteorological weeks (SMW)) of 1990 to 2014 was utilized for this study. The data sets included the adult male moth population of $S$. litura caught in pheromone traps deployed @ $5 /$ ha in the experimental farms and weather variables [maximum temperature $\left(\mathrm{MaxT}^{\circ} \mathrm{C}\right)$, minimum temperature $\left(\mathrm{MinT}{ }^{\circ} \mathrm{C}\right)$, rainfall $(\mathrm{RF} \mathrm{mm})$, morning relative humidity (MRH \%) and evening relative humidity (ERH \%)] of nineteen weeks in a season beginning from end of June (26 SMW) to second week of November (44 SMW) for twenty five years (1990-2014) from University of Agricultural Sciences, Dharwad, Karnataka.

\section{Trend analysis for climatic variability}

Time series data of climatic variables for 30 years (1985-2014) were tested for normality using Jarque-Bera (1987) test statistic. TheMann-Kendall non-parametric test (Mann, 1945, Kendall 1975) was applied to detect and describe the long-term changes in climatic variables.

The standardized MK statistic $Z_{M K}$ follows the standard normal distribution with mean zero and unit variance. The null hypothesis of no trend in the series was rejected when $\mathrm{S}$ and were significantly different from zero. If a significant trend was found the rate of change was calculated using Sen's slope estimator (Sen 1968).

\section{Determining the period of $S$. litura peak severity and modelling}

The time of maximum occurrence of S. litura was examined over the historical data and the period of maximum trap catches (i.e., population) in respect of individual seasons were obtained. The weekly pheromone trap catches of male moths were grouped into three categories viz., low (0-200), medium (200-400) and high (>400) using cumulative square root frequency method (Delenius and Hodges 1959) that transformed the continuous data on population occurrence of S. litura into an ordinal scale. All the weather variables were normalized in view of their heterogeneous measurement units by subtracting mean value followed by division using standard deviation to have zero mean value and unity variance before use in modelling. The maximum severity of S. litura was modeled using ordinal logistic model with the help of historical data pertaining to trap catches of S. litura and weather variables pertaining to Kharif season (26 to 44 SMW). In order to determine the significant weather variables influencing the $S$. litura peak severity, correlation analysis was done considering the populationof S. litura of 34 SMW with weather variables lagged up to five weeks (2933 SMW). 


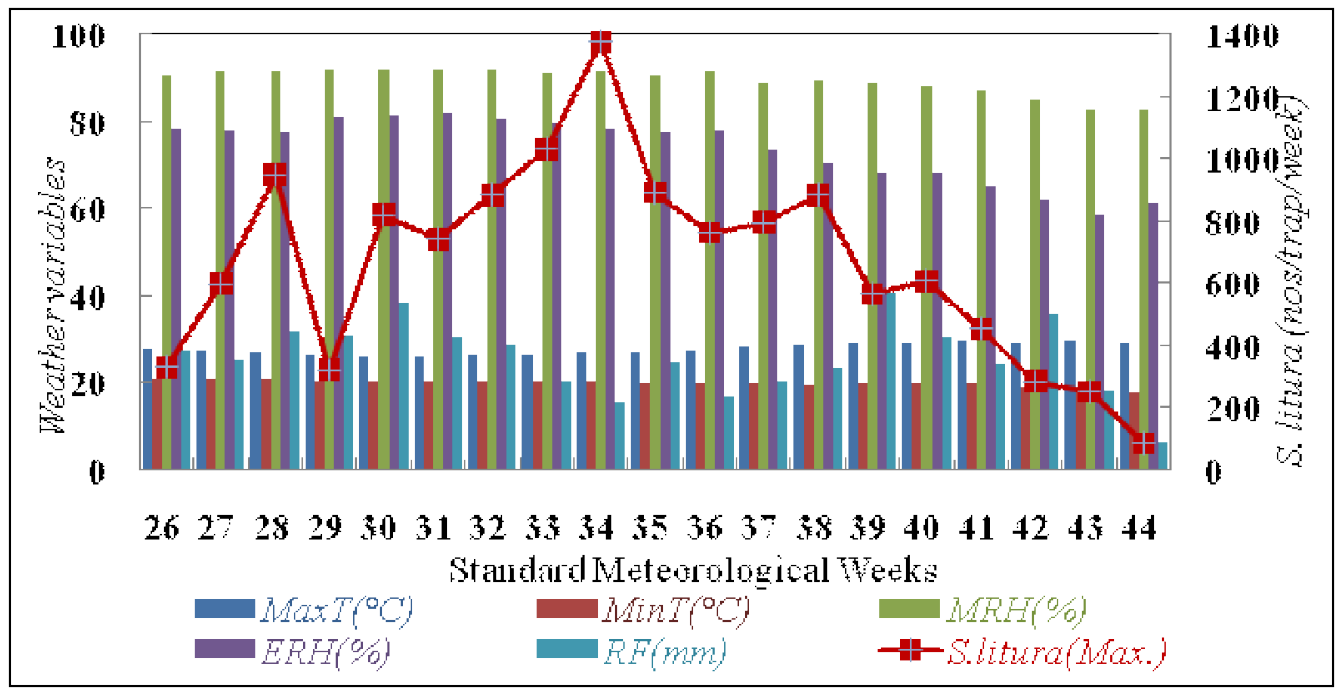

Fig. 1: Weekly distribution of weather variables and peak S. litura occurrence

Let $\mathrm{Y}$ denote the severity of pest population occurrence graded on scales from low to high having their natural order. If the response variable $Y$ has categories then there are ways to dichotomize the response variable:. Also let is the reference level of classification then there will be two equations, one for each non-reference relative to reference category to describe the relationship between response and independent variables.

The mathematical form of the equation is defined as $P[Y \geq k \mid X]=\frac{1}{1+\exp \left[-\left(\alpha_{k}+\sum_{i=1}^{p} \beta_{i} X_{i k}\right)\right]} \ln \left(\frac{P[Y \geq k \mid X]}{P[Y<k \mid X]}\right)=\alpha_{k}+\sum_{i=1}^{p} \beta_{i} X_{i k}$ and odds is given by

$o d d s[Y \geq k \mid X]=\frac{P[Y \geq k \mid X]}{P[Y<k \mid X]}=\exp \left(\alpha_{k}+\sum_{i=1}^{p} \beta_{i} X_{i k}\right) \quad k=1,2, \ldots c-1$

where is the $i^{\text {th }}$ independent variable belonging to the categories . (intercept) and (slope) are the regression coefficients. Hence, after fitting the equation we obtain the $\log$ of odds ratio for the $i^{\text {th }}$ observation belongs to the category. The adequacy of developed model performance was measured using Akaike Information Criterion (AIC) and Schwarz Criterion (SC). All the analyses were done using SAS 9.3.To compute the probabilities of higher ordered levels of the response variable $\mathrm{Y}$, sign were adjusted when reporting the estimate of model parameter as SAS provide probability for lower ordered categories.

\section{RESULTS AND DISCUSSION}

\section{Peak severity of S. litura and OLR using weather variables}

Figure 1 presents the maximum severity of S. litura moth catches (nos/trap/week) vis a vis the mean weather variables in respect of the individual (26-44) SMWs over Kharif seasons of 25 years (1990-2014). The long term averages over seasons for each of the SMWs indicated a continuously increasing population between 30 and 36 SMWs and the peak at 34 SMW.

The ordinal categories of $S$. litura population viz., low (0-200), medium (200-400) and high (>400) made using cumulative square root frequency method also adhered to the expert opinion. The classification revealed the highest occasions of low incidence $(76.42 \%)$ followed by medium $(12.42 \%)$ and high $(11.16 \%)$ categories considering the overall occurrences across all individual SMWs of all years. However, the proportion of severity categories of low, medium and high was 44, 28 and $28 \%$, respectively when only the peak period of occurrence (34 SMW) was accounted (Table 1).

Highly increased occurrences of medium and high severity ( $56 \%$ together) during the period of peak population over the low severity (44\%), justified the requirement of prediction or the model development exclusive for the peak severity of $S$. litura over the prediction for the individual weeks.

Jarque Bera test used for checking normality for all series of weather variables indicated the non-normality of all the weather variables except maximum temperature (Table 2). Hence, the analysis for long-term changes in climatic variables was carried out using Mann Kendall non parametric test.

The trend analysis performed on each weather variable pertaining to 19 weeks (26 to 44 SMW) of Kharif 
Table 1: Distribution of S. litura population on an ordinal scale

\begin{tabular}{llll}
\hline Category & \multicolumn{2}{l}{ Population of S. litura } & \multicolumn{2}{l}{ Contribution of SMWs to ordinal scale } \\
& $($ nos/trap/week) & Based on 26-44 SMW & Based on 34 SMW \\
\hline Low & $<200$ & $363(76.42)$ & $11(44.00)$ \\
Medium & $200-400$ & $59(12.42)$ & $7(28.00)$ \\
High & $>400$ & $53(11.16)$ & $7(28.00)$ \\
Total & & $475(100.00)$ & $25(100.00)$ \\
\hline
\end{tabular}

Note: Figure in parenthesis are the percentages of ordinal category

Table 2: Normality and trend test statistics for weather variables during 1985-2014

\begin{tabular}{lrrrrrrr}
\hline Weather variable & $\begin{array}{r}\text { Jarque-Bera } \\
\text { test statistic }\end{array}$ & p-value & $\tau$ & $\mathrm{Z}_{\mathrm{MK}}$ & $\mathrm{p}$-value & $\beta$ & $\begin{array}{c}\text { Trend } \\
\text { Direction }\end{array}$ \\
\hline MaxT $\left({ }^{\circ} \mathrm{C}\right)$ & 3.24 & 0.1970 & -0.0003 & -0.0114 & 0.9909 & 0.0000 & $\downarrow$ \\
$\operatorname{MinT}\left({ }^{\circ} \mathrm{C}\right)$ & 1266.48 & $<0.0001$ & 0.1062 & 3.7707 & 0.0002 & 0.0008 & $\uparrow$ \\
MeanT $\left({ }^{\circ} \mathrm{C}\right)$ & 25.17 & $<0.0001$ & 0.0468 & 1.6635 & 0.0962 & 0.0004 & $\uparrow$ \\
MRH $(\%)$ & 2065.27 & $<0.0001$ & -0.1669 & -5.9265 & 0.0000 & -0.0057 & $\downarrow$ \\
ERH $(\%)$ & 307.65 & $<0.0001$ & -0.1760 & -6.2513 & 0.0000 & -0.0184 & $\downarrow$ \\
MeanRH $(\%)$ & 370.80 & $<0.0000$ & -0.1839 & -6.5291 & 0.0000 & -0.0121 & $\downarrow$ \\
RF(mm) & 633.18 & $<0.0000$ & 0.0583 & 2.0743 & 0.0381 & 0.0056 & $\uparrow$ \\
\hline
\end{tabular}

Table 3: Parameter estimates and standard error for ordinal logistic regression

\begin{tabular}{lllll}
\hline Variable & Estimate \pm SE & Wald test & p-value & Odds ratio \\
\hline Intercept 2 & $-1.3216 \pm 0.5888$ & 5.0387 & 0.0248 & - \\
Intercept 1 & $0.5540 \pm 0.5165$ & 1.1503 & 0.2835 & - \\
MaxT & $2.1533 \pm 0.8348$ & 6.6531 & 0.0099 & 8.61 \\
MRH & $1.8523 \pm 0.7649$ & 5.8634 & 0.0155 & 6.37 \\
\hline
\end{tabular}

Table 4: Predictive performance of the developed model

Category Observed Model Prediction (no. of years) (no. of

\begin{tabular}{lllll} 
& years $)$ & Low & Medium & High \\
\hline Low & 9 & $\mathbf{6}$ & 2 & 1 \\
Medium & 7 & 2 & $\mathbf{5}$ & 0 \\
High & 6 & 1 & 1 & $\mathbf{4}$ \\
\hline
\end{tabular}

season using 30 years data (1985 to 2014) yielded measures of MK test statistics ( $\tau, Z_{M K}$ and $\beta$ ) indicating the direction, significance and magnitude of the trend, respectively. It is clear that the mean temperature, minimum temperature and rainfall for the study period showed an increasing trend, and morning and evening relative humidity and their mean showed a decreasing trend (Table 2). The ideal condition for the growth of the S. litura is at $27^{\circ} \mathrm{C}$ temperature and increasing development rate with temperature up to $30^{\circ} \mathrm{C}$ (Rao et al. 2014) for many locations including Dharwad has been reported. In the present study, although maximum temperature showed a decreasing trend that was not significant (Table 2), the minimum and the mean temperature had shown significantly increasing trends leading to the expected increase of the $S$. litura population in the future.

The correlation analysis of $S$. litura populationwith lagged weeks of each of weather variables revealed significant positive correlationfor maximum temperature of 32 and 33 SMWs as well as significant negative correlation withevening relative humidity of 32 SMW justifying the importance of modelling $S$.liturapopulation dynamics with lagged weather variables.

The developed model of OLR included all the weather variables viz., maximum temperature $\left(\operatorname{MaxT}{ }^{\circ} \mathrm{C}\right)$, minimum temperature $\left(\mathrm{MinT}^{\circ} \mathrm{C}\right)$, rainfall $(\mathrm{RF} \mathrm{mm})$, morning relative humidity ( $\mathrm{MRH} \%$ ) and evening relative humidity $(\mathrm{ERH} \%)$ pertaining to 32 and 33 SMWs. Several combinations of 
Table 5: Validation using future seasons

\begin{tabular}{|c|c|c|c|c|c|c|c|}
\hline \multirow[t]{2}{*}{ Year } & \multicolumn{2}{|c|}{ Predictors } & \multicolumn{3}{|c|}{ Predicted probabilities } & \multicolumn{2}{|c|}{ Severity } \\
\hline & $\operatorname{MaxT}\left({ }^{\circ} \mathrm{C}\right)$ & MRH $(\%)$ & $\operatorname{Pr}(\mathrm{Y}=2)$ & $\operatorname{Pr}(\mathrm{Y}=1)$ & $\operatorname{Pr}(\mathrm{Y}=0)$ & Predicted & Observed \\
\hline 2012 & -0.1199 & 1.1041 & 0.6143 & 0.2979 & 0.0877 & 2 & 2 \\
\hline 2013 & 0.4549 & 0.5610 & 0.6675 & 0.2615 & 0.0709 & 2 & 0 \\
\hline 2014 & -0.8536 & 0.7088 & 0.1363 & 0.3709 & 0.4928 & 0 & 0 \\
\hline
\end{tabular}

*: $\mathrm{Y}=2,1$ and 0 indicate high, medium and low S. lituraseverity, respectively at peak period

explanatory variables were evaluated, and it was found that the maximum temperature (MaxT) and morning relative humidity (MRH) prior to two weeks of the peak severity of S. litura were the major influencing factors for the pest development. Hence OLR model was arrived at by using these two weather variables. The value of score test statistic ( failed to reject the null hypothesis of proportional odds assumption, and confirmed that the odds ratio of assessing the effect of an exposure variable for any of the category comparison is same. The positive regression coefficients that were significant for the predictor variables namely, maximum temperature $\left(\operatorname{MaxT}{ }^{\circ} \mathrm{C}\right)$ and morning relative humidity (MRH \%) of 32 SMW (Table 3) indicated their role in predicting the severity levels of $S$. litura as to low or medium or high. The estimated odds ratio for the effect of maximum temperature and morning relative humidity of 32 SMW over other weather variable is 8.61 and 6.37, respectively. Results suggested that for each degree increase in maximum temperature during $32 \mathrm{SMW}$, the odds of being high pest attack (as opposed to lower or medium) increased by a multiple of 8.6 as compared to the odds of being high or medium (as opposed to low) increasing by 6.4 times for each per cent rise in the morning relative humidity (Table 3 ).

The OLR model with lowest AIC (51.71) and SC (53.89) value is considered the best. AIC and SC penalize the $\log$-likelihood by the number of predictors in the model. The goodness of fit of OLR model assessed in terms of the observed and the predicted number of years under the different ordinal categories of S.litura severity viz., low, medium and high specified higher frequencies of predictions always associated with the respective expected category (Table 4).

The overall prediction accuracy of model was $68 \%$ ( 15 exact predictions out of a total of 22 years), with $71 \%$ adherence for medium and $66 \%$ for low and high pest severity levels. Table 5 presents the predicted probabilities for high, moderate and low category of pest severity levels for three seasons (2012-2014). The developed model predicted the S. litura severity correctly for the years 2012 and 2014 as high and low, respectively. The deviation of prediction during 2013 (high as against low) could have arisen due to the skewed population with reference to different categories of pest severity as well as small size of data.

\section{CONCLUSION}

Effect of climate variability on pest species is multidimensional and its impact on crop damage is dependent on the species in question and its growth pattern. In the present investigation, the systematic procedure of identifying the period of peak severity of S. litura, trend analysis of the climatic variables and establishing pestweather relations for the groundnut cropping system of Dharwad (Karnataka) formed the foundation for the application of ordinal logistic regression model for forewarning. The proportional odds model takes into account the effect of an exposure on ordered pest severity and yields odds ratios. The maximum temperature and morning relative humidity were found important towards prediction of peak severity (34 SMW), and the extremes of any one or both of these factors could alter drastically the severity of $S$. litura in the future years. Ordinal logistic model predicted $S$. litura peak severity in two out of the three occasions indicating its prediction accuracy greater than $65 \%$ which is reliable given the observed circumstances of changing climate at Dharwad. The inclusion of derived weather variables such as number of dry spells, rainy days and extremes of weather (unseasonal events of fog, heat wave, cyclone etc., ) could form aspects of further studies. The reliability portrayed for S. litura through use of OLR could well form the basis for development of forecast system for S. litura of additional locations or crops or for other similar insect pests.

\section{ACKNOWLEDGEMENT}

Authors gratefully acknowledge the funding of Indian Council of Agricultural Research (ICAR) for undertaking the current research study, "National Initiative on Climate Resilient Agriculture (NICRA)". 


\section{REFERENCES}

Agresti,A. (2002). Analysis of ordinal categorical data. Wiley, New York.

Ananth, C.V. and Kleinbaum, D.G.(1997). Regression model for ordinal responses: Areview of methods and applications. Int JEpidemiol., 26(6): 1323-1333.

Anderson, J.A. (1984). Regression and ordered categorical variables. J. R. Stat. Soc., Ser B. 46:1-30.

Cammell, M. and Knight, J.(1992). Effects of climatic change on the population dynamics of crop pests. Adv Ecol Res., 22: $117-162$.

Delenius, T. and Hodges. J. L. (1959). Minimum variance stratification. J. Am. Stat. Assoc., $54: 88-101$.

Dhaliwal, G.S., Jindal, V. and Dhawan,A.K. (2010). Insect pest problems and crop losses: Changing trends. Indian $J$ Entomol., 371: 1-7

FAOSTAT. (2014). Food and agriculture oraganisation of the United Nations. http://faostat.fao.org/site/567/ default.aspx.

GoI.(2014). Agricultural Statistics at a Glance, Directorate of Economics and Statistics, Department of Agriculture and Cooperation, Ministry of Agriculture, Government of India.

Jarque, C. M., Bera, A.K. (1987). A test for normality of observations and regression residuals. Int. Stat. Rev., 55 (2): 163-172.

Kendall, M.G.(1975). RankCorrelation Methods. Charles Griffin, London.
Mann, H.B. (1945). Non-parametric tests against trend. Econometrica., 13:245-259.

NCIPM, NICRA(2011). Manual for groundnut pest Surveillance. ICAR-National Research Centre for Integrated Pest Management, New Delhi, Directorate of Groundnut Research, Gujarat \& Central Research Institute for Dryland Agriculture, Hyderabad.

Porter, J.H., Parry, M.L. and Carter, T.R. (1991). The potential effects of climatic change on agricultural insect-pests. Agr Forest Meteorol., 57:221-240.

Parsad,Y.G., Gayathri, M., Prabhakar, M., Jeyakumar,P., Vennila, S., Rao, A.V.M.S., Rao, I.B., Rao, K.V., Rao, G., Rao, V.U.M.(2013). Population dynamics of Spodoptera litura outbreak on soybean vis a vis rainfall events. $J$. Agrometeorol., 15(Special Issue): 37-40.

Rao, M.S., Swathi, P., Manimanjari, D., Rao, A.C.R. and Maheswari, M. (2014). Effect of climate change on Spodoptera litura Fab. on peanut: A life table approach. Crop Prot., 66: 98-106.

Roy, S.S. and Balling, R.C. (2004). Trends in extreme daily precipitation indices in India. Int JClimatol., 24: 457466.

Sen, P.K. (1968). Estimates of the regression coefficient based on Kendall's tau. J. Am. Stat. Assoc., 63:1379-1389.

Yadav, R., Tripathi S.K., Pranuthi, G. and Dubey, S.K. (2014). Trend analysis by Mann-Kendall test for precipitation and temperature for thirteendistricts of Uttarakhand.J. Agrometeorol., 16(2):37-40. 